\title{
Compressive strength Prediction recycled aggregate incorporated concrete using Adaptive Neuro Fuzzy System and Multiple Linear Regression
}

\author{
Funso Falade a.", Taim Iqbal a \\ a Department of Civil Engineering, University of Lagos, Nigeria.
}

${ }^{*}$ Corresponding Author ffalade@unilag.edu.ng (Funso Falade)

Received : 19 03 2019 Accepted : 07 05 2019

\begin{abstract}
Compressive strength of concrete, renowned as one of the most substantial mechanical properties of concrete and key factors for the quality assurance of concrete. In the present study, two different data driven models, i.e., Adaptive Neuro Fuzzy Inference System (ANFIS), and Multiple Linear Regression (MLR) were used to predict the 28 days compressive strength of recycled aggregate concrete (RAC). 16 different input parameters, including both dimensional and non dimensional parameters, were used for predicting the 28 days compressive strength of concrete. The present study established that estimation of 28 days compressive strength of recycled aggregate concrete was performed better by ANFIS in comparison to MLR. Besides, the performance of data driven models with and without the non dimensional parameters is explored. It was observed that the data driven models show better accuracy when the non dimensional parameters were used as additional input parameters. Furthermore, the effect of each non dimensional parameter on the performance of each data driven model is investigated and 28 days compressive strength of concrete is examined.
\end{abstract}

Keywords: ANFIS, MLR, Data driven models, Recycled aggregate concrete.

\section{Introduction}

The depleting natural resources and their scarcity has always been one of the most important issues. Therefore, reducing the impact and protecting the environment has always been an important issue to scientists. One of the way to decrease this impact may be using construction and demolition waste (C\&D) as replacement to natural resources. Adding the recycled aggregates to concrete mixes is termed as recycled aggregate concrete (RAC). Scientists have investigated the effect of RA on characteristics of concrete such as tensile strength, compressive strength, etc [1,2]. Using RA as a replacement to natural aggregates would result in the reduction in the compressive strength of RAC since they hold attached mortar to the aggregates. In addition, the prevailing criterion for the concrete with RA is the reduction of the density of RAC because of the water absorption by the mortar on the aggregates. Furthermore, the workability of RAC is less than the concrete with conventional aggregates because of the same explained water absorption. Finally, replacing the natural aggregates by RA which would lead to the reduction of the compressive strength might be because of the weaker connections between mortar and RCA [1,3]. Studies have also shown that the level of the compressive strength of RAC highly depends on the strength of RA and therefore, the strength of RAC made of RA with lower strength is less than that of concrete made of RA with higher strength, and the extent of the reduction is dependent on many factors, such as the type of concrete, $\mathrm{W} / \mathrm{C}$ ratios, moisture percentages, replacement ratios, etc $[1,4]$. In order to estimate the compressive strength of concrete, data driven models which are based on measured data can be a good replacement for this extensive testing. Scientists have used data driven models broadly in the field of civil engineering. Jiang et al. have found the Artificial Neural Network capable in predicting the concrete corrosion of sewers [5]. Have concluded that the Imperialist Competitive Algorithm is an efficient technique in estimating the corrosion current density of reinforced concrete [6]. Padmini et al. have successfully used the neuro fuzzy models in determining the ultimate bearing capacity of shallow foundations [7]. The present study proposes two different data driven models, i.e., Adaptive Neuro Fuzzy Inference System (ANFIS), and Multiple Linear Regression (MLR) models to predict the 28 days compressive strength of concrete using 16 different input variables. In addition, the performance of data driven models with and without the non dimensional parameters is explored. Furthermore, the effect of each nondimensional parameter on performance of all the presented data driven models is investigated. Finally, the effect of number of input parameters on prediction of 28 days compressive strength of concrete is studied. 


\section{Data preparation}

In the present study, a total of 249 data sets was collected from fresh experiments performed by authors $[1,3$, 8 23]. The parameters were divided into three categorizations of mandatory elements, nondimensional elements, and output elements described in the following:

Mandatory Elements (Raw Data): The weight per cubic meter is considered as raw data based on standard mix design procedures followed worldwide [3]. In this study, the mandatory parameters are cement (C), natural fine aggregate (NFA), recycled fine aggregate (RFA), natural coarse aggregates $10 \mathrm{~mm}$ (NCA10), natural coarse aggregates $20 \mathrm{~mm}$ (NCA20), recycled coarse aggregates 10 $\mathrm{mm}$ (RCA10), recycled coarse aggregates $20 \mathrm{~mm}$ (RCA200), admixture (AD), and water (W) [24].

Table 1 Compressive strength range for patterns

\begin{tabular}{|c|c|c|}
\hline S1.No & $\begin{array}{c}\text { Compressive strength } \\
\text { range }\left(\mathrm{kg} / \mathrm{m}^{3}\right)\end{array}$ & $\begin{array}{c}\text { Number of } \\
\text { patterns }\end{array}$ \\
\hline 1 & $0 \sim 20$ & 14 \\
\hline 2 & $20 \sim 40$ & 109 \\
\hline 3 & $40 \sim 80$ & 97 \\
\hline 4 & $80 \sim 100$ & 31 \\
\hline 5 & $60 \sim 80$ & 4 \\
\hline 6 & $100 \sim 150$ & 1 \\
\hline & Total & 256 \\
\hline
\end{tabular}

(B) Non-dimensional Elements: Any ratio of the mandatory parameters is considered as the non dimensional elements. In this study, the non dimensional parameters are water $\sim$ cement ratio $(\mathrm{W} / \mathrm{C})$, sand aggregate ratio (S/A), water to total materials ratio $(\mathrm{W} / \mathrm{T})$, replacement ratio of recycled aggregate to natural aggregate by volume (RR), and aggregate to cement ratio $(\mathrm{A} / \mathrm{C})$.

(C) Output Element (Dependent Parameter): In this study, the 28 days compressive strength of recycled aggregate concrete is considered as the output parameter.

It is worth mentioning that in this study both the categorization of (A) and (B) are used as input variables and the categorization (C) is used as output variable in the data driven modeling purposes. In addition, the number of 28 days compressive strength patterns in each specific interval is shown in Table 1

\section{Estimation techniques}

\subsection{Multiple Linear Regression model (MLR)}

Regression models generally estimate the level of correlation between the input and output variables and determine their relationship form. Linear regressions are mostly fitted by the least squares approach, however, they might be fitted using other methods, like by minimizing the "lack of fit" in some other norms or by minimizing the penalized version of the least squares loss function as in ridge regression. Basically, the linear regression is divided into two categorizations of simple and Multiple Linear Regression.

If the aim is to estimate the linear correlation between one predictor and one criterion variable, the model is assumed as the simple linear regression (SLR), however, if the goal is to predict the linear correlation between two or more predictors and still one criterion variable, the model is called Multiple Linear Regression (MLR). It is worth mentioning that the MLR is the most common form of linear regression analysis and every value of the independent variable is associated with a value of dependent variable.

\subsection{Adaptive Neuro Fuzzy Inference System (ANFIS)}

Adaptive Neuro Fuzzy Inference System (ANFIS) is identified as a universal estimator for responding to complex problems. ANFIS is a class of adaptive, multi-layer and feed forward networks which is comprised of input-output variables and a fuzzy rule base of the Takagi- Sugeno type. The fuzzy reasoning mechanism of ANFIS model with two fuzzy if -then rules for a first order Sugeno fuzzy model is expressed as [25].

Rule 1: IF $\mathrm{x}$ is $\mathrm{A} 1$ and $\mathrm{y}$ is $\mathrm{B} 1$, THEN $\mathrm{f} 1=\mathrm{p} 1 \mathrm{x}+\mathrm{q} 1 \mathrm{y}+\mathrm{r} 1$.

Rule 2: IF $\mathrm{x}$ is $\mathrm{A} 2$ and $\mathrm{y}$ is $\mathrm{B} 2$, THEN $\mathrm{f} 2=\mathrm{p} 2 \mathrm{x}+\mathrm{q} 2 \mathrm{y}+\mathrm{r} 2$.

The framework of ANFIS contains five layers, which act differently from each other; however, the nodes of the same layer perform similar to each other. The structure of ANFIS is shown in Fig. 1.

\section{Comparison of MLR and ANFIS models}

In order to compare the MLR, ANN, and ANFIS models, 14 different concrete mix parameters have been chosen as input variables. These input parameters are divided into two categorizations of mandatory and non dimensional elements.

\subsection{Multiple Linear Regression model (MLR)}

In the MLR model, the data are divided into two subsets of training and test. The proportions of training and testing are characterized based on the fact that the general structure of the model is constructed with respect to the training data set. Therefore, the amount of data in the training set plays a significant role.

The total number of specimens was equal to 256 in which $82 \%$ of them (i.e. 211 specimens) were chosen for the training step, and $18 \%$ of them (i.e. 39 specimens) were selected for the test step. 


\section{Layer 1}

\section{Layer 4}

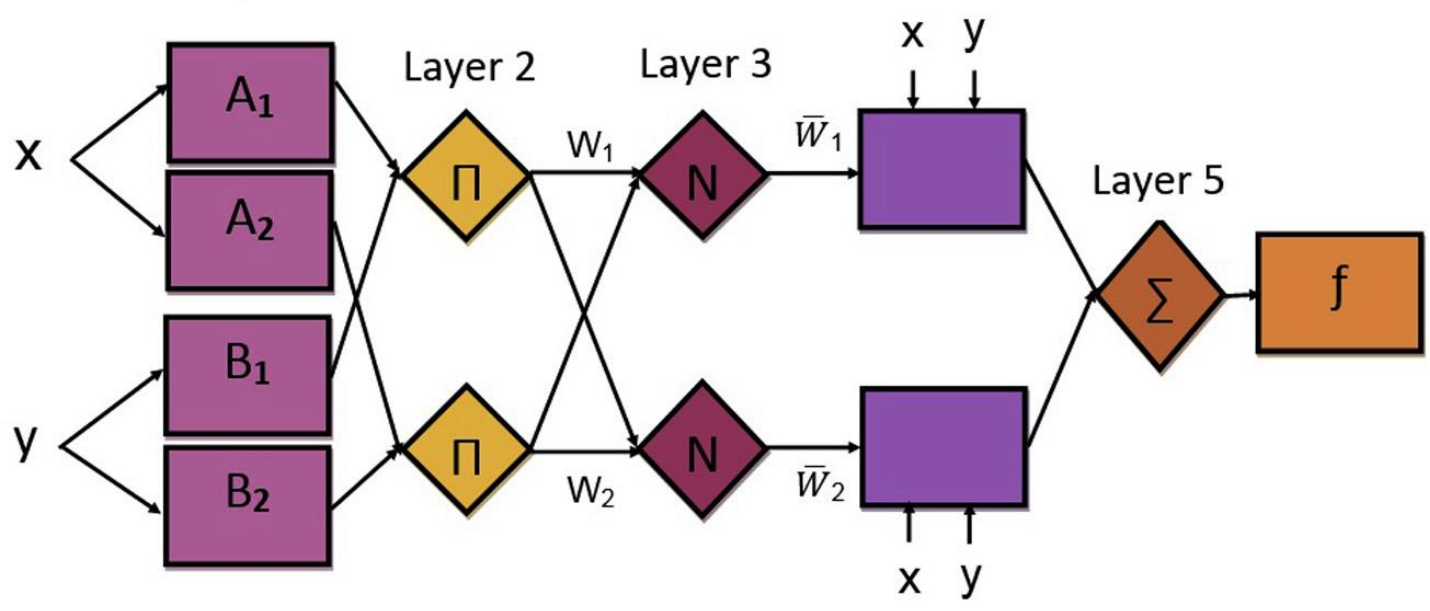

Fig 1. Structure of ANFIS model with two input variables.

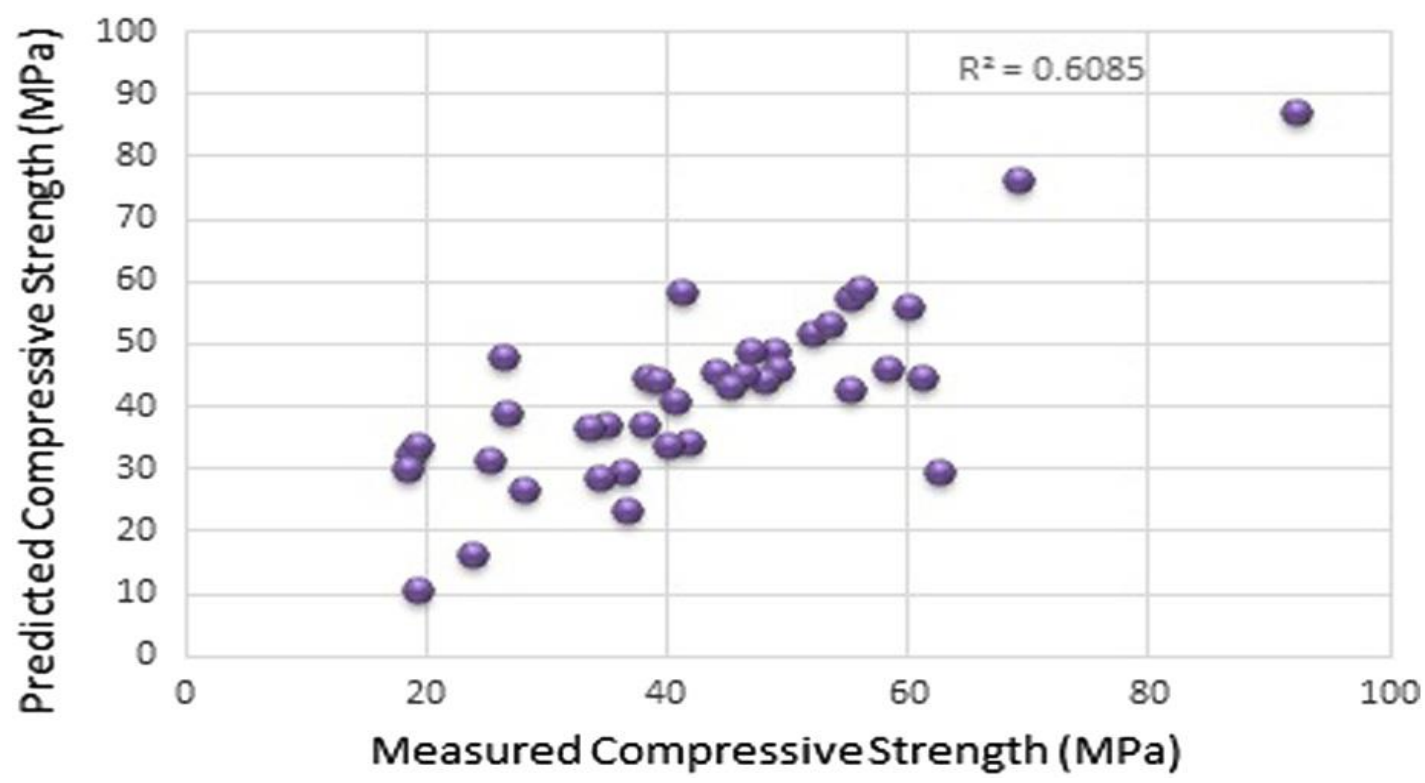

Fig 2. Relationship between the measured and predicted compressive strength of the test step of the MLR model.

Fig. 2 shows the relationship between the measured and predicted compressive strength of the MLR model for the test step. As it is shown in the Fig, the $\mathrm{R}^{2}$ value of the test step in MLR model is determined as 0.6085. In addition, the SSE and MSE are calculated as 3880.67 and 99.504 , respectively. To conclude, MLR model did not show the high level of capability in predicting the 28 days compressive strength of concrete. This might be due to the fact that there is nonlinear relationship between the studied parameters and MLR model is mostly able to find out the linear relationship between the response and predictor variables.

\subsection{Adaptive Neuro Fuzzy Inference System (ANFIS)}

In this study, the ANFIS modeling was performed in Matlab software and the proportions of training, validation (check), and testing were selected the same as the ones selected for ANN modeling. Fig. 3 shows the measured and predicted data for 28 days compressive strength of concrete for the training step. Fig. 3 demonstrates good coincidence of target and output data which indicate the capability of the ANFIS model.

The coefficient of determination $\left(\mathrm{R}^{2}\right)$ shows the level of capability of the ANFIS model in predicting the 28 compressive strength of concrete. 


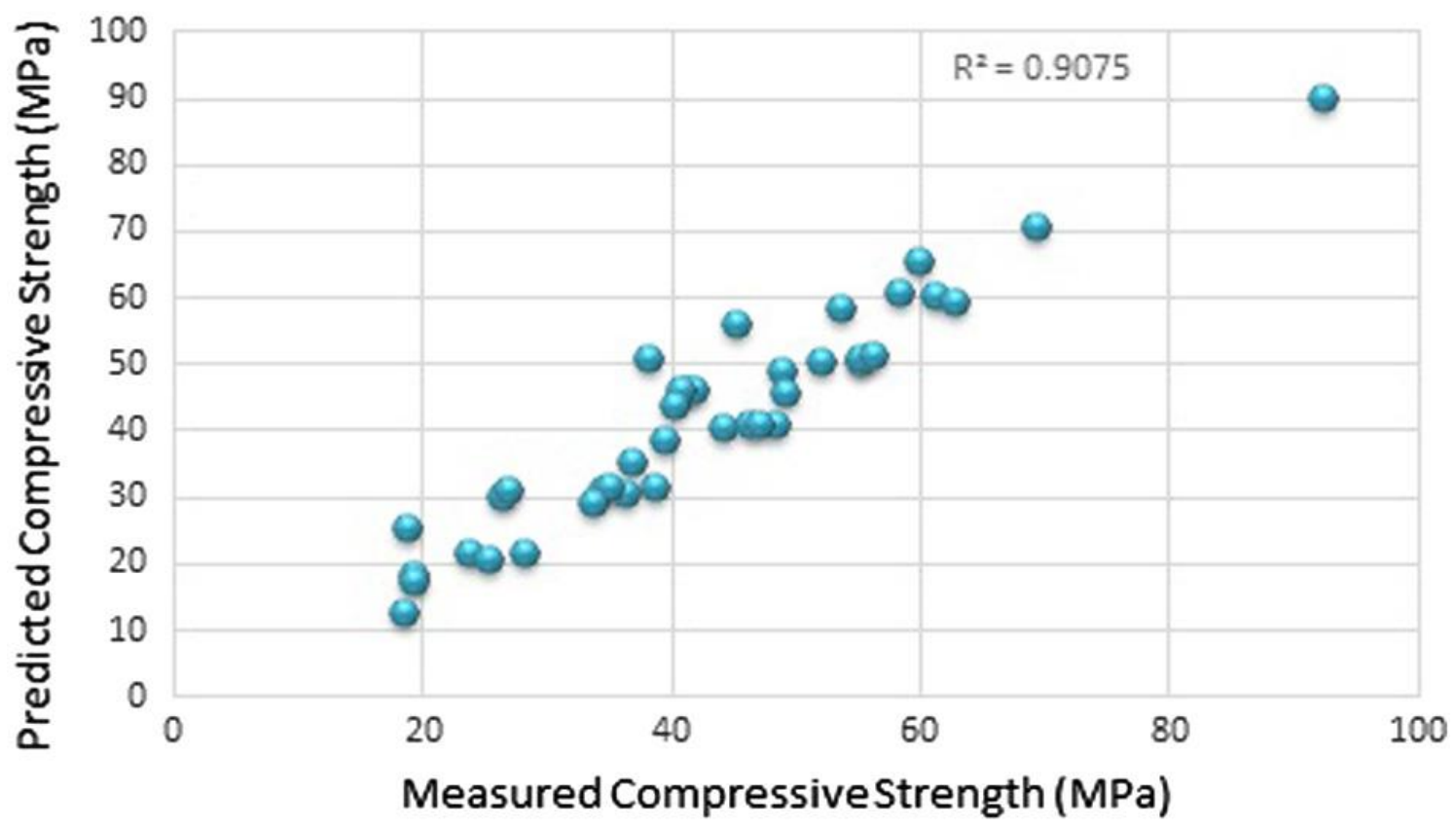

Fig 3. Comparison between the "Target" and "Output" parameters for "Training" step in ANFIS model.

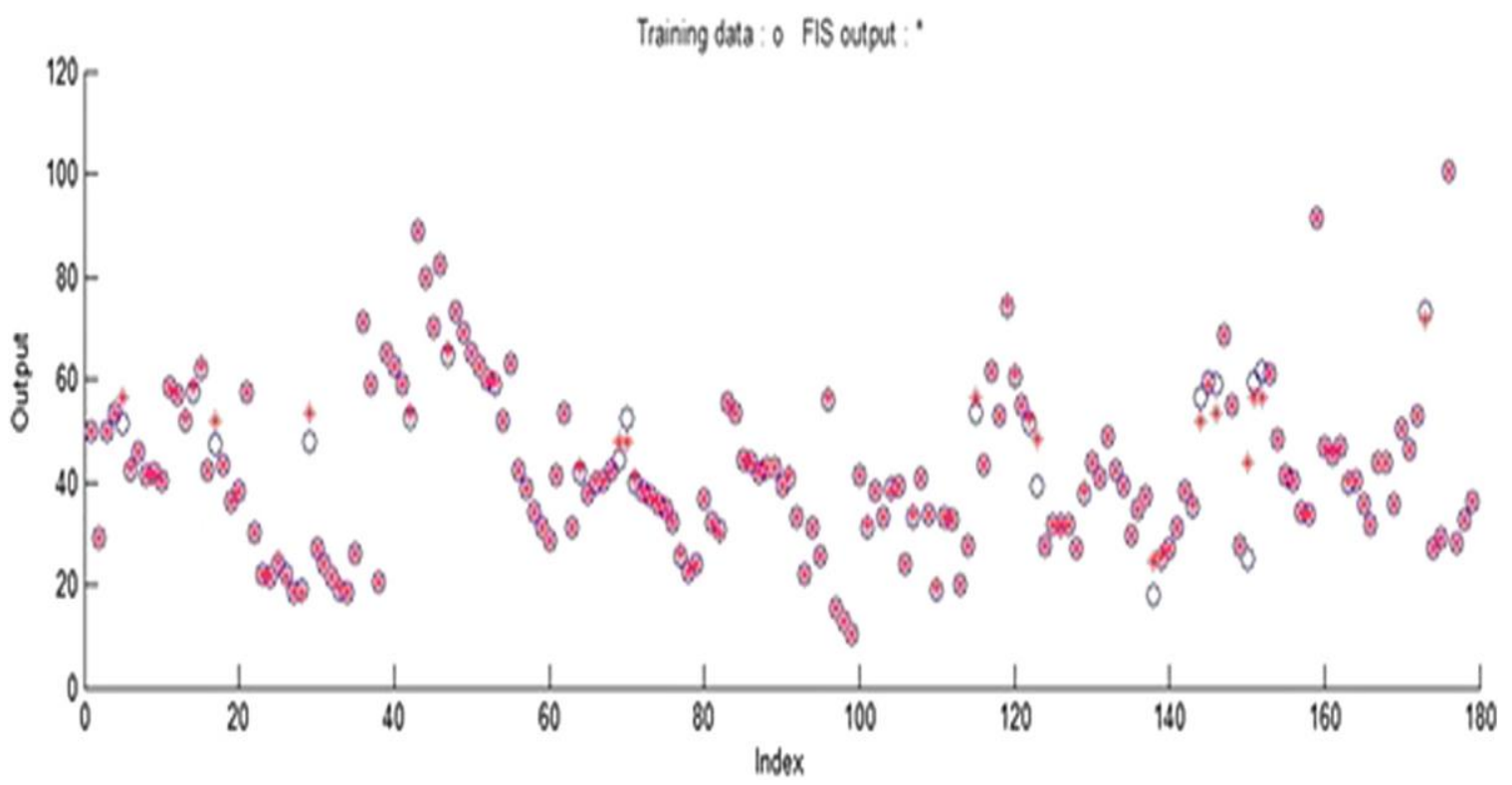

Fig 4. Relationship between the measured and predicted compressive strength of the test step of the ANFIS model.

As it is shown in the Fig, the coefficient of determination for the test step of the ANFIS model is determined as $\mathrm{R}^{2}=$ 0.9075. In addition, the SSE and MSE are determined as 992.67 and 25.45, respectively. To conclude, the ANFIS model is found to be capable in estimating the compressive strength of concrete with satisfactory performance.

In addition, Fig. 4 shows the relationship between the measured and predicted compressive strength for the testing of the ANFIS model.

\section{Conclusion}

In this paper, three different data driven models, i.e., Adaptive Neuro
Fuzzy Inference System (ANFIS), and Multiple Linear Regression (MLR) were used to predict the 28 days compressive strength of recycled aggregate concrete (RAC).

The following outcomes have been taken out from this research:

(1) MLR model with R2 $=0.6085, \mathrm{SSE}=3880.67$, and MSE $=99.5043$ was found not to be efficient enough in predicting the 28 days compressive strength of concrete. This may be because of the nonlinear relationship between the studied elements and MLR model is mostly able to find out the linear relationship between the input and output variables. 
(2) ANFIS model with $\mathrm{R}^{2}=0.9075, \mathrm{SSE}=992.67$, and MSE $=25.4530$ was found to be talented in approximating the 28 days compressive strength of concrete.

(3) ANFIS model was found to be efficient in predicting the 28 days compressive strength of concrete, however MLR was found not to be capable enough in the same predicting purposes. In other words, MLR model is better to be used for preliminary mix design of concrete, and ANFIS Model is recommended in the mix design optimization and in the case of higher accuracy requirements.

(4) The advantage of ANFIS might be due to the fact that the relationship between the studied variables is nonlinear and the model is more capable in determining the nonlinear relationship between the response and predictor variables.

(5) Though MLR model is capable enough to estimate the 28 days compressivestrength of concrete, ANFIS was found more efficient than MLR.

\section{References}

[1] A. Ajdukiewicz and A. Kliszczewicz, Influence of recycled aggregates on mechanical properties of HS/HPC, Cem. Concr. Compos., 24 (2002) 269279 .

[2] N. Deshpande, S.S. Kulkarni and N. Patil, Effectiveness of using coarse recycled concrete aggregate in concrete, Int. J. Earth Sci. Eng., 4 (2011) 913-919.

[3] N. Deshpande, S. Londhe and S. Kulkarni, Modeling compressive strength of recycled aggregate concrete by artificial neural network, model tree and non linear regression, Int. J. Sustainable Built Environ., 3 (2014) 187-198.

[4] F. Khademi, M. Akbari and S.M.M. Jamal, Prediction of compressive strength of concrete by data driven models, i Manager's J. Civ. Eng., 5 (2005) 16.

[5] J.S. Jang, ANFIS: adaptive network based fuzzy inference system, IEEE Trans. Systems Man Cybern., 23 (1993) 665-685.

[6] M. Nikoo, P. Zarfam and M. Nikoo, Determining displacement in concrete reinforcement building with using evolutionary artificial neural networks, World Appl. Sci.J., 16 (2012) 1699-1708.

[7] D. Padmini, K. Ilamparuthi and K.P. Sudheer, Ultimate bearing capacity prediction of shallow foundations on cohesionless soils using neurofuzzy models, Comput. Geotech., 35 (2008) 33-46.
[8] Y.V. Akbari, N.K. Arora, M.D. Vakil, Effect on recycled aggregate on concrete properties, Int. J. Earth Sci. Eng., 4 (2011) 924-928.

[9] A. Katz, Properties of concrete made with recycled aggregate from partially hydrated old concrete, Cem. Concr. Res., 33 (2003) 703-711.

[10] A.K. Padmini, K. Ramamurthy, M.S. Mathews, Relative moisture movement through recycled aggregate concrete, Mag. Concr. Res., 54 (2002) 377-384.

[11] E. Dapena, P. Alaejos, A. Lobet and D. Pe'rez, Effect of recycled sand content on characteristics of mortars and concretes, J. Mater. Civ. Eng., 23 (2010) 414-422.

[12] G. Fathifazl, A. Abbas, A.G. Razaqpur, O.B. Isgor, B. Fournier and S. Foo, New mixture proportioning method for concrete made with coarse recycled concrete aggregate, J. Mater. Civ. Eng., 21 (2009) 601-611.

[13] J. Hu, Z. Wang and Y. Kim, Feasibility study of using fine recycled concrete aggregate in producing self consolidation concrete, Journal of Sustainable Cement based Material, 2 (2013) 20 34.

[14] T.C. Hansen, H. Narud, Strength of recycled concrete made from crushed concrete coarse aggregate, Concr. Int., 5 (1983) 79-83.

[15] K. Duangthidar, Recycled Aggregate Concrete for Structural Applications (Ph.D. thesis), University of Western Sydney, 2010.

[16] C.S. Poon, Z.H. Shui, L. Lam, H. Fok and S.C. Kou, Influence of moisture states of natural and recycled aggregates on the slump and compressive strength of concrete, Cem. Concr. Res., 34 (2004) 31-36.

[17] K. Ramadevi and R. Chithra, Concrete using recycled aggregates, Int. J. Civ. Eng. Technol., 8 (2017) 413 419

[18] A. Domingo Cabo, C. La'zaro, F. Lo'pez Gayarre, M.A. Serrano Lo'pez, P. Serna and J.O. Castan o Tabares, Creep and shrinkage of recycled aggregate concrete, Constr. Build. Mater., 23 (2009) 25452553.

[19] S. Kou, Reusing Recycled Aggregates in Structural Concrete (Ph.D Thesis). The Hong Kong Polytechnic University 2006.

[20] P. Pereira, L. Evangelista and J. De Brito, The effect of superplasticizers on the mechanical performance of concrete made with fine recycled concrete aggregates, Cem. Concr. Compos., 34 (2012) 10441052. 
[21] A. Gonc,alves, A. Esteves and M. Vieira, Influence of recycled concrete aggregates on concrete durability. Proc. RILEM, PRO 40: use of recycled materials in buildings and structures, International RILEM Conference on the Use of Recycled Materials in Buildings and Structures 8 11 (2004) 8 11.

[22] V. Corinaldesi, Mechanical and elastic behaviour of concretes made of recycled concrete coarse aggregates, Constr. Build. Mater., 24 (2010) 16161620.

[23] F. Khademi and K. Behfarnia, Evaluation of concrete compressive strength using artificial neural network and multiple linear regression models, Iran Univ. Sci. Technol., 6 (2016) 423-432.

[24] S.M. Mosavi and A.S. Nik, Strengthening of steelconcrete composite girders using carbon fibre reinforced polymer (CFRP) plates, Sadhana, 40 (2015) 249-261.

About The License

(C) 2019 The Authors. This work is licensed under a Creative Commons Attribution 4.0 International License which permits unrestricted use, provided the original author and source are credited. 